\title{
Impact of Urgent and Emergency Care Vanguards on Delayed Transfers of Care in England
}

Gintare Malisauskaite*1, Karen Jones ${ }^{1}$, Stephen Allan ${ }^{1}$, Daniel Roland ${ }^{1}$, Yvonne Birks², Kate Baxter², Kate Gridley²

*Correspondence: G.Malisauskaite@kent.ac.uk Personal Social Services Research Unit (PSSRU), University of Kent, Office CC228, Cornwallis Central, Canterbury, CT2 7NF, UK

\footnotetext{
${ }^{1}$ Personal Social Services Research Unit (PSSRU), School of Social Policy, Sociology and Social Research (SSPSSR), University of Kent, UK

2 Social Policy Research Unit (SPRU), Department of Social Policy and Social Work, University of York, UK
} 


\section{Abstract}

Objectives: To assess the relationship between Urgent and Emergency Care (UEC) Vanguards, which include as an aim the integration of healthcare and social care sectors, and Delayed Transfers of Care (DTOC) at Local Authority level in England.

Methods: Difference-in-difference and fixed effects panel estimations were used to compare DTOC between UEC partner site Local Authorities with nonUEC Local Authorities employing quarterly data on days of DTOC from Local Authorities in England for the period 2010 to 2017. Robustness checks included employing Ordinary Least Squared (OLS) and synthetic control estimations; differences between the UEC and non-UEC sites were checked prior to the start of the Vanguards.

Results: A statistically significant negative relationship was found between UEC Vanguards and DTOC rates that is robust to various specification checks with no indication of UEC participant sites having lower DTOC rates prior to the start of the initiative.

\section{Conclusions:}

UEC Vanguards appear to be associated with $40.5 \%$ lower DTOC rates at 1\% significance level compared with other English Local Authorities. The empirical evidence indicates a statistically significant impact; however, more research is required to explain the reasons for this relationship.

\section{Keywords:}

Delayed Transfers of Care, Urgent and Emergency Care Vanguards, integration policy 


\section{Background}

Delayed Transfers of Care (DTOC) is a term used to describe situations where patients are medically fit to be discharged from a hospital to home or further care settings but the process is delayed. DTOC has attracted increased attention from policy makers and health and social care professionals (1), due to recent increases (2), an estimated $£ 820$ million annual cost (3), and delayed hospital discharge has been associated with decreased subsequent participation in activities of daily living, frailty, increased age, high comorbidity, cognitive impairment, and dependency (4-10).

Attempts to address the costs associated with DTOC have inspired some innovative policy approaches to integrating social and health care over the last few years, including Better Care Fund (11), Integrated Care Pioneers (12) and recently New Models of Care - Vanguards (13). Vanguards set out to help improve integration of services with five different approaches (13):

- Acute care collaboration - link local hospitals to improve clinical and financial viability.

- Urgent and emergency care - improve coordination of services and reduce pressure on $A \& E$ departments.

- Enhanced health in care homes - improve and integrate health, care and rehabilitation services for older people in care homes.

- Multi-speciality community providers - move specialist care into the community from hospitals.

- Integrated primary and acute care systems - join up GP, hospitals, community and mental health services. 
This paper examines the relationship between Urgent and Emergency Care (UEC) Vanguards and DTOC rates specifically, since discharge planning from acute care was identified as one of the challenges by the UEC Vanguards (14). Since DTOC may be directly affected by the effectiveness of communication between health and social care providers, DTOC rates may be a useful proxy for some aspects of integration. DTOC has previously been used as a criterion for evaluating the success of health and social care integration policy initiatives (15).

To date, research related to DTOC is somewhat scarce. Most research considers challenges related to the discharge of older people: appropriate future support, suitable discharge destinations, and how policies are put into practice (16-19), and how lack of social care supply may increase DTOC (20). Concerns over the integration of services in general are also considered (21, 22). As part of a wider study examining the role of social care in DTOC (23) we examined the link between UEC Vanguards and DTOC rates.

\section{Methods}

Data were collected for 150 English Local Authorities (here onwards - LAs, excluding City of London and Isles of Scilly) for the time period between 2010 quarter 4 and 2017 quarter 4 (150 LAs, 29 quarters, 4,350 observations). The model specification built on that developed in Roland et al. (24) with minor adjustments:

$$
{ }_{D T O C} C_{i t}=\alpha+V_{i t} \beta_{1}+C_{i t} \beta_{2}+u_{i t}
$$


Where the dependent variable $D T O C_{i t}$ is expressed either as number of DTOC days or as its natural logarithm. Subscript $i$ indicates a Local Authority, $t$ time, in quarters and $\alpha$ is a constant. The UEC Vanguards took effect in August 2015 (quarter 3) and included 29 Local Authorities as partners (13). Vanguard partners were identified using the dummy variable $V_{i t}(1=$ after implementation, 2015 quarter 3, 0 = before or not this Vanguard partner), and $\beta_{1}$ is the coefficient of interest for the analysis, showing the effect of the UEC Vanguards on DTOC. Finally, $C_{i t}$ is a vector of control variables.

The analysis controlled for the following factors associated with LA-level DTOC: demographics and needs (carer's allowance, disability living allowance, total population in LA, and percentage of population above 65 years old), LA structure (type, size in square metres, percentage of people living in rural areas, the number of Clinical Commissioning Groups (CCGs) each LA interacted with, and care home bed supply), economic variables (jobseeker's allowance, pension credit, house prices, percentage of older people who own houses with mortgages, and percentage of older people who own houses outright). Further details of the data are available in Appendix Table A1.

Both OLS and fixed effects specifications of the model were estimated (25, p. 285). All regressions used cluster-robust standard errors centred at LAs and year dummies for each year since 2010. Total number of days of DTOC and its natural logarithm were both used as the dependent variable, the latter was preferred because of the skewed distribution of DTOC. A Hausman test found that fixed effects specifications was preferred to random effects, although results with the latter specification were comparable. 
Synthetic control estimations (26-27) were run as robustness checks, to create a control unit that matched the main characteristics of the treated unit (i.e. derived average of all UEC Vanguard partner sites). This allowed for a more credible prediction of the counterfactual, and was created using characteristics of local authorities that were not UEC Vanguards.

\section{Results}

[Table 1]

Descriptive statistics

Table 1 gives descriptive statistics. From the last quarter of 2010 to the last quarter of 2017, the average number of DTOC days was 2,755 per English LA per quarter. $6.7 \%$ of the sample observations were UEC Vanguard partner sites.

[Figure 1]

Figure 1 compares average number of DTOC days (ratio to LA population) per quarter for LAs in UEC Vanguards compared to those not in UEC Vanguards. The increase in DTOC days for LAs in UEC Vanguards was lower.

Fixed effects panel regression

Table 2 reports the main results from OLS and fixed effects panel regression estimations in column 1 . The relationship between the UEC Vanguards and DTOC is consistently negative and statistically significant. In the preferred specification, UEC Vanguards are associated with 40.5\% lower DTOC rates at $1 \%$ significance level (95\% confidence interval: $22.4-58.5 \%)$. Reduction in DTOC is larger when estimated with fixed effects (FE) than with OLS (1063 
days vs. 863 and $40.5 \%$ vs. $25.3 \%$ ). This is likely due to $\mathrm{FE}$ accounting for differences between panel units over time, separating and capturing the relationship with UEC better.

[Table 2]

\section{Robustness checks}

Table 2 also presents some of the robustness checks we employed. One of the possible interpretations for the observed results may be that sites participating in UEC Vanguards could have been selected based on better DTOC rates. There is no publically available information of specific selection criteria so we tested for this running the model (1) using two modifications:

a) without identifying the start of the UEC Vanguard, checking for an overall difference between UEC participating sites and others over the entire period of time of data (column 2);

b) using only data prior to 2015 , the start of the initiative (column 3).

The findings show there was no statistically significant relationship between UEC Vanguards and DTOC in these alternative specifications that suggests that UEC Vanguard sites did not have lower DTOC rates prior to the start.

[Figure 2]

Figure 2 depicts the predictions of synthetic control estimations. The figure show that since the beginning of UEC Vanguards partner sites had consistently lower average DTOC rates than would be predicted without the Vanguards, and the difference is sizeable (in line with FE). The significant dip in DTOC days just prior to the start of UEC Vanguards suggests that some 
form of preparation with regard to integration and DTOC could have taken place in the participating sites.

\section{Discussion}

\section{Main findings}

Our findings suggest that LAs that were part of UEC Vanguards had significantly lower DTOC than non-UEC sites on average. Overall DTOC rates rose substantially in the second quarter of 2015 until the end of 2016, potentially explained by severe cuts to social care (28), however, they rose significantly less in UEC Vanguard sites. We found no evidence suggesting that UEC Vanguard sites had lower DTOC rates prior to becoming Vanguards but are unable to rule out the possibility that they might have been in a better position to reduce DTOC, possibly due to other as yet unidentified factors. It is difficult to pinpoint the reasons why UEC Vanguards influence DTOC rates and it is likely any explanation lies within other policies and initiatives associated with being in a Vanguard. One potential explanation is the channel shift modelling tool which supports integration of services, communication and cooperation between hospital and community based services (29). Channel shift interventions include planning discharge from time of admission, discharging for further assessment ('discharge to assess') and rapid response services. Consequently, detailed analyses regarding specifics of UEC Vanguards should be carried out in future research. Additionally, this analysis does not account for different levels of exposure to UEC Vanguard influence in each LA, and this could be another route of enquiry. 


\section{Limitations}

We cannot claim the relationship between UEC and DTOC to be causal. There is no publically available information on the criteria of selection into different Vanguards, which might inform explanations and analysis. Further work on specific policies used within UEC Vanguard sites, including qualitative analysis and exposure levels to UEC Vanguards by LA, could help untangle potential reasons for the association between UEC Vanguards and DTOC.

\section{Conclusions}

The introduction of the UEC Vanguards seems to be related to significantly lower DTOC for UEC partner sites, highlighting important implications for the National Health Service and social care, alongside individuals discharged from hospital. However, it is difficult to isolate the impact of the UEC Vanguards from other Government integration policies, together with the austerity climate facing the care sector.

\section{Abbreviations}

UEC: Urgent and emergency care vanguard;

DTOC: delayed transfers of care;

OLS: Ordinary least squares;

LA: Local Authority;

CCG: Clinical Commissioning Group;

FE: Fixed effects panel regression model. 


\section{Declarations}

Ethics Approval and consent to participate

Not applicable.

\section{Consent for publication}

Not applicable.

\section{Availability of data and materials}

The datasets used and/or analysed during the current study are available from the corresponding author on reasonable request.

\section{Competing interests}

The authors declare that they have no competing interests.

\section{Funding}

This study was funded by the National Institute for Health Research School for Social Care Research. The views expressed in this independent research publication are those of the authors and not necessarily those of the NIHR SSCR, the National Institute for Health Research or the Department of Health and Social Care.

\section{Author's contributions}

GM conceived the statistical methodology, performed the statistical analysis and drafted the manuscript; KJ contributed to the conception, study design and the final writing of this paper; SA contributed to the study design, 
statistical methodology and the final writing of this paper; DR contributed to the statistical methodology and the final writing of this paper; YB critically revised the draft and contributed to the final writing of this paper; KB critically revised the draft and contributed to the final writing of this paper; KG critically revised the draft and contributed to the final writing of this paper.

\section{Acknowledgements}

Not applicable.

\section{References}

1. NHS Providers. The rise of delayed transfers of care. London: NHS Providers; 2017. https://nhsproviders.org/the-rise-of-delayed-transfersof-care. Accessed Oct 2019.

2. NHS England. Delayed Transfers of Care. Leeds: NHS England; 2011 [updated 2019]. https://www.england.nhs.uk/statistics/statistical-workareas/delayed-transfers-of-care/. Accessed Oct 2019.

3. National Audit Office. Discharging older patients from hospitals. London: National Audit Office; 2016. https://www.nao.org.uk/wpcontent/uploads/2015/12/Discharging-older-patients-from-hospital.pdf. Accessed Apr 2019.

4. Bo M, Fonte G, Pivaro F, et al. Prevalence of and factors associated with prolonged length of stay in older hospitalized medical patients. Geriatr Gerontol Int. 2016;16(3):314-321.

5. Challis D, Hughes J, Xie C, Jolley D. An examination of factors influencing delayed discharge of older people from hospital. Int $J$ Geriatr Psychiatry. 2014;29(2):160-168.

6. Costa AP, Hirdes JP. Clinical characteristics and service needs of alternate-level-of-care patients waiting for long-term care in Ontario hospitals. Healthc Policy. 2010;6(1):32-46.

7. Costa AP, Poss JW, Pierce T, Hirdes JP. Acute care inpatients with longterm delayed-discharge: Evidence from a Canadian health region. BMC Health Serv Res. 2012;12:172-182.

8. McClaran J, Tover R, Duarte E. Long hospital stays and need for alternate level of care at discharge. Does family make a difference for elderly patients? Can Fam Physician. 1996;42:449-461. 
9. Rojas-García A, Turner S, Pizzo E, Hudson E, Thomas J, Raine R. Impact and experiences of delayed discharge: A mixed-studies systematic review. Health Expect. 2018;21(1):41-56.

10. Bai AD, Dai C, Srivastava S, Smith CA, Gill SS. Risk factors, costs and complications of delayed hospital discharge from internal medicine wards at a Canadian academic medical centre: retrospective cohort study. BMC Health Serv Res. 2019; doi: 10.1186/s12913-019-4760-3.

11. NHS England. Better Care Fund. London: NHS England; 2013. https://www.england.nhs.uk/ourwork/part-rel/transformation-fund/bcfplan/. Accessed Oct 2019.

12. NHS England. Integrated Care Pioneers. London: NHS England; 2014. https://www.england.nhs.uk/new-care-models/integrated-carepioneers/. Accessed Oct 2019.

13. NHS England. New Care Models: Vanguards - developing blueprint for the future of NHS and care services. London: NHS England; 2016.

https: / /www.england.nhs.uk/wpcontent/uploads/2015/11/new_care_models.pdf. Accessed Mar 2019.

14. NHS England. New Care Models: supporting the vanguards Urgent and Emergency Care (UEC) vanguards: summary. London: NHS England; 2015. https: / /www.england.nhs.uk/wp-content/uploads/2015/12/uecsupport-package-summary.pdf. Accessed Oct 2019.

15. Forder J, Caiels J, Harlock J, Wistow G, Malisauskaite G, Peters M, Marczak J, D’Amico F, Fernandez JL, Fitzpatrick R, Jones K. A systemlevel evaluation of the Better Care Fund: Final report. Personal Social Services Research Unit; 2018. https://www.pssru.ac.uk/pub/5424.pdf. Accessed Oct 2019.

16. Coffey A. Discharging older people from hospital to home: what do we know? Int. J. Older People Nurs. 2006;1:141-150.

17. Glasby J, Littlechild R, Pryce K. All dressed up and nowhere to go? Delayed hospital discharges and older people. J. Health Serv. Res. Pol. 2006;11(1):52-58.

18. Swinkels A, Mitchell T. Delayed transfer from hospital to community settings: the older person's perspective. Health Soc. Care Community. $2008 ; 17(1): 45-53$.

19. Shaw J, Kontos P, Martin W, Victor C. The inter-relation between policy and practice for transitions from hospital to home: an ethnographic case study in England's National Health Service. BMC Health Serv Res. 2014;P111. doi:10.1186/1472-6963-14-S2-P111.

20. Gaughan J, Gravelle H, Siciliani L. Testing the bed-blocking hypothesis: does nursing and care home supply reduce delayed hospital discharges? J.Health Econ. 2015;24(1):32-44. 
21. Fernandez J, McGuire A, Raikou M. Hospital coordination and integration with social care in England: The effect on post-operative length of stay. J.Health Econ. 2018;61:233-243.

22. Goddard M, Mason A. Integrated care: A pill for all ills? Int $J$ Health Policy Manag. 2017;6(1):1-3.

23. Jones K, Allan S, Malisauskaite G, Birks Y, Baxter K, Gridley K, Roland D. The influence of social care on delayed transfers of care (DTOC) among older people: Final report. Personal Social Services Research Unit. 2020. https://kar.kent.ac.uk/id/eprint/77826. [In press].

24. Roland D, Malisauskaite G, Jones K, Birks Y, Baxter K, Gridley K, Allan S. Identifying unexplained DTOC at Local Authority level. 2020. [Forthcoming].

25. Wooldridge $\mathrm{J}$ M. Econometric analysis of cross section and panel data. $2^{\text {nd }}$ ed. Cambridge: The MIT Press; 2010.

26. Abadie A, Diamond A, Hainmueller J. Synthetic Control Methods for Comparative Case Studies: Estimating the Effect of California's Tobacco Control Program. J. Am. Stat. Assoc. 2010;105(490):493-505.

27. Abadie A, Diamond A, Hainmueller J. Comparative Politics and the Synthetic Control Method. Am. J. Political Sci. 2015;59(2):495-510.

28. Bate A. Delayed transfers of care in the NHS. Briefing paper Nr. 7415, London: House of Commons Library; 2017. https://commonslibrary.parliament.uk/research-briefings/cbp-7415/. Accessed Oct 2019.

29. NHS England. Urgent and emergency care channel shift model. London: NHS England; 2015. https://www.england.nhs.uk/urgent-emergencycare/about-uec/uec-channel-shift/. Accessed Oct 2019.

[Appendix] 


\section{Tables and Figures}

Table 1: Descriptive statistics

\begin{tabular}{|c|c|c|}
\hline Variable & Mean & Min/Max \\
\hline \multicolumn{3}{|l|}{ Dependent variables: } \\
\hline DTOC days & 2755.394 & $0 / 26733$ \\
\hline DTOC(log) & 7.438 & $0 / 10.194$ \\
\hline \multicolumn{3}{|l|}{ Explanatory variables: } \\
\hline UEC Vanguard & 0.067 & $0 / 1$ \\
\hline JSA ratio & 0.026 & $0.001 / 0.09$ \\
\hline $\mathrm{PC}$ ratio $(65+)$ & 0.235 & $0.062 / 0.691$ \\
\hline CA ratio & 0.011 & $0.004 / 0.027$ \\
\hline DLA ratio $(65+)$ & 0.087 & $0.025 / 0.257$ \\
\hline Care home beds (log) & 7.553 & $5.451 / 9.461$ \\
\hline Population (log) & 12.598 & $10.519 / 14.257$ \\
\hline Population $65+$ ratio & 0.166 & $0.06 / 0.286$ \\
\hline Rural or hub (\%) & 17.507 & $0 / 100$ \\
\hline No. CCGs to LA & 5.660 & $1 / 21$ \\
\hline House prices $(£, \log )$ & 12.343 & $11.443 / 14.62$ \\
\hline Owning house ratio $(65+)$ & 0.075 & $0.013 / 0.126$ \\
\hline Owning house outright ratio $(65+)$ & 0.069 & $0.011 / 0.115$ \\
\hline $\operatorname{Area}\left(\mathrm{m}^{2}\right)$ & 86839.430 & $1213 / 803761$ \\
\hline CCG dummy & 0.655 & $0 / 1$ \\
\hline \multicolumn{3}{|l|}{ LA type: } \\
\hline Metropolitan & 0.240 & $0 / 1$ \\
\hline London & 0.213 & $0 / 1$ \\
\hline County & 0.180 & $0 / 1$ \\
\hline \multicolumn{3}{|l|}{ Year: } \\
\hline 2010 & 0.034 & $0 / 1$ \\
\hline 2011 & 0.138 & $0 / 1$ \\
\hline 2012 & 0.138 & $0 / 1$ \\
\hline 2013 & 0.138 & $0 / 1$ \\
\hline 2014 & 0.138 & $0 / 1$ \\
\hline 2015 & 0.138 & $0 / 1$ \\
\hline 2016 & 0.138 & $0 / 1$ \\
\hline 2017 & 0.138 & $0 / 1$ \\
\hline No of obs. & & \\
\hline
\end{tabular}


Figure 1: Average DTOC days over time

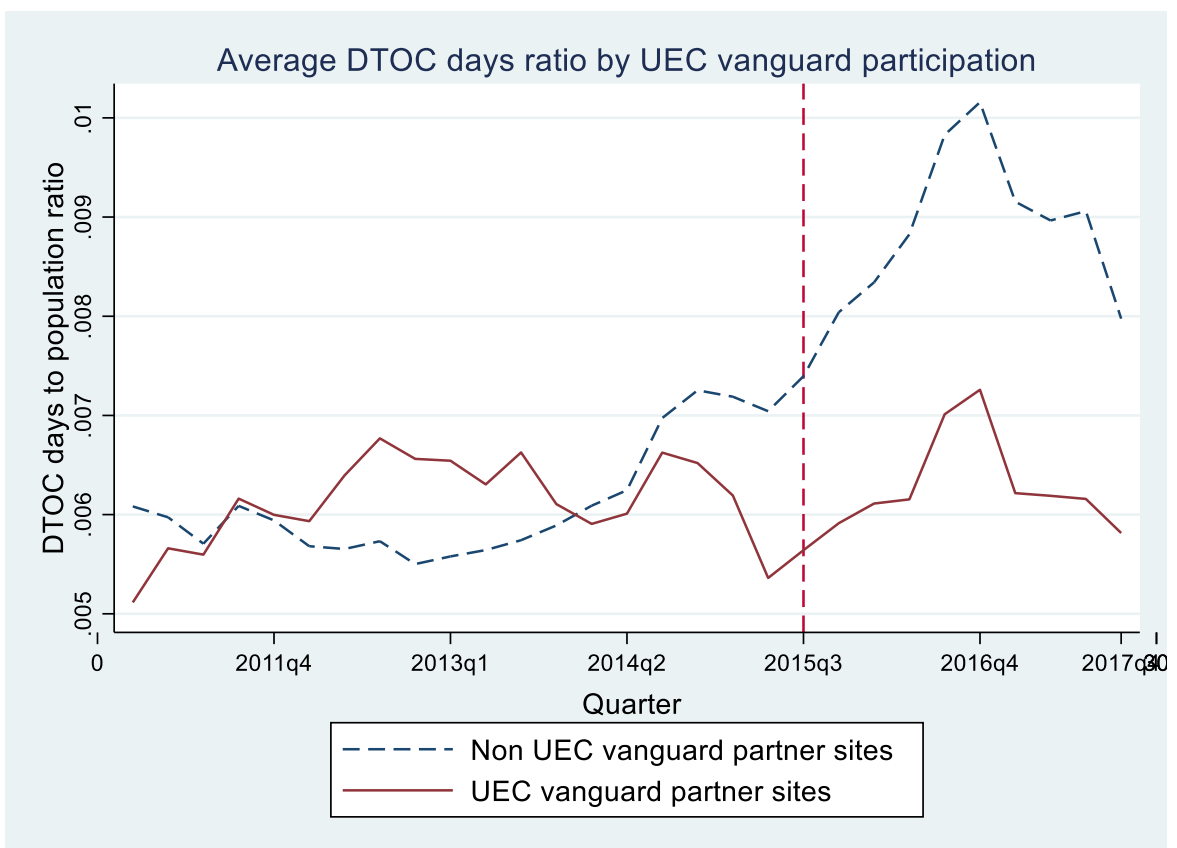

Note: UEC Vanguard partner sites include 29 LA's (12).

Table 2: Relationship between UEC Vanguards and DTOC

\begin{tabular}{llccc}
\hline \hline Estimation method & Dependent & $1)$ & $2)$ & $3)$ \\
& variable & & & \\
\hline OLS & DTOC (days) & $-862.935^{* * *}$ & -322.209 & 180.772 \\
& & $(284.705)$ & $(243.911)$ & $(218.522)$ \\
& DTOC (log) & $-0.253^{* * *}$ & -0.047 & 0.132 \\
Panel regression, FE & & $(0.088)$ & $(0.079)$ & $(0.095)$ \\
& DTOC (days) & $-1063.251^{* * *}$ & - & - \\
& & $(253.854)$ & & - \\
\hline Number of observations & DTOC (log) & $-\mathbf{0 . 4 0 5 * * *}$ & - & 2550 \\
\hline
\end{tabular}

Note: Columns: 1) Main specification, exploring effects of different estimators and expressions of the dependent variable, main result in bold; 2) UEC Vanguard sites are identified with a binary variable without distinguishing the starting point of this Vanguard; 3) same as 2) only using sample prior to 2015.

Other variables included in the estimations but not in the table above include LAs' demographics, structure, benefits, other economic variables and year dummies, specified in Methodology section; more details of variable construction available in the Appendix.

Robust standard errors in parentheses.

'- variable omitted due to collinearity.

$* * *-p<1 \%, * *-p<5 \%, *-p<10 \%$ 
Figure 2: Synthetic control estimations

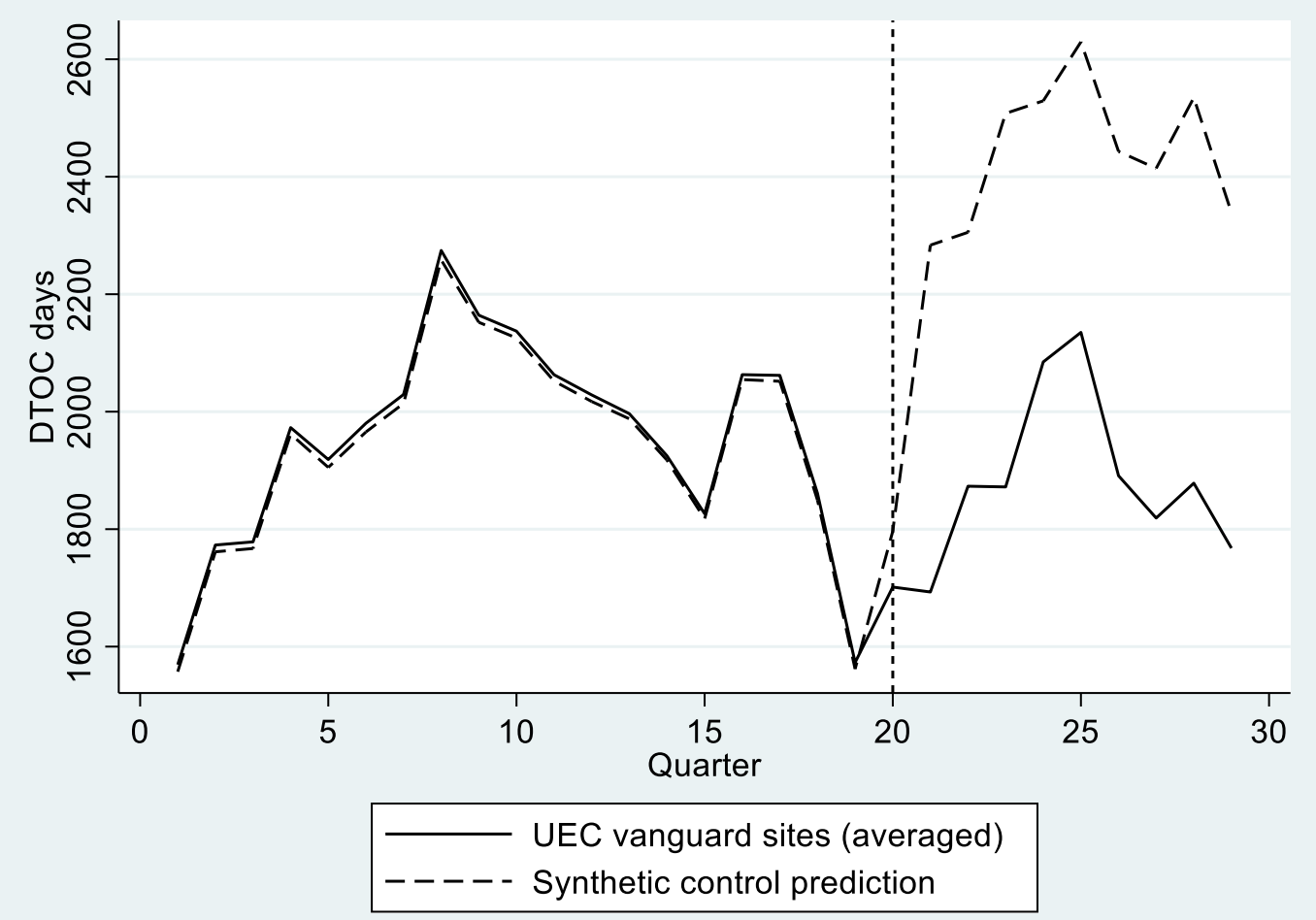




\section{Appendix}

Table A1: Definition of variables

\begin{tabular}{|c|c|c|c|}
\hline Variable & Explanation & Frequency & Source \\
\hline Dependent: & & & \\
\hline DTOC (days) & $\begin{array}{l}\text { Number of days any patient experienced } \\
\text { delayed discharge from hospital }\end{array}$ & $\mathrm{Q}$ & NHS/E \\
\hline $\begin{array}{l}\text { DTOC (log) } \\
\text { Explanatory: }\end{array}$ & Natural logarithm of DTOC(days) & $\mathrm{Q}$ & NHS/E \\
\hline UEC Vanguards & $\begin{array}{l}1 \text { if one of } 29 \text { LA's participating in this } \\
\text { Vanguard and it is onwards and after } 2015 \\
\text { quarter } 3,0-\text { otherwise }\end{array}$ & $\mathrm{F}$ & NHS/E \\
\hline Care home beds(log) & $\begin{array}{l}\text { Natural logarithm of the number of care home } \\
\text { beds available in the LA }\end{array}$ & A & CQC \\
\hline CA Ratio & $\begin{array}{l}\text { Percentage of all population that receives } \\
\text { Carer's Allowance }\end{array}$ & Q & ONS \\
\hline DLA Ratio(65) & $\begin{array}{l}\text { Percentage of older population }(65+\text { years }) \\
\text { that receives Disability Living Allowance }\end{array}$ & Q & ONS \\
\hline JSA Ratio & $\begin{array}{l}\text { Percentage of all population that receives } \\
\text { Jobseeker's Allowance }\end{array}$ & $\mathrm{Q}$ & ONS \\
\hline PC Ratio(65) & $\begin{array}{l}\text { Percentage of older population ( } 65+\text { years) } \\
\text { that receives Pension Credit }\end{array}$ & Q & ONS \\
\hline Population(log) & Natural logarithm of the LA's population & A & ONS \\
\hline $65+$ ratio & $\begin{array}{l}\text { Percentage of older people }\left(65^{+}\right) \text {in the } \\
\text { population }\end{array}$ & A & ONS \\
\hline House prices $(\log )$ & $\begin{array}{l}\text { Natural logarithm of average house prices in } \\
\text { LA }\end{array}$ & Q & LandReg \\
\hline Owned house & $\begin{array}{l}\text { Percentage of older people }\left(65^{+}\right) \text {that own a } \\
\text { house with mortgage }\end{array}$ & $\mathrm{F}$ & ONS \\
\hline $\begin{array}{l}\text { Owned house } \\
\text { (outright) }\end{array}$ & $\begin{array}{l}\text { Percentage of older people }\left(65^{+}\right) \text {that own a } \\
\text { house outright }\end{array}$ & $\mathrm{F}$ & ONS \\
\hline LA type & $\begin{array}{l}\text { Type of Local Authority: Metropolitan, } \\
\text { Unitary, London and County }\end{array}$ & $\mathrm{F}$ & Gov \\
\hline Area & Local Authority's size $\left(\mathrm{m}^{2}\right)$ & $\mathrm{F}$ & Gov \\
\hline Rural and hub ratio & $\begin{array}{l}\text { Percentage of people living in rural areas and } \\
\text { hub towns }\end{array}$ & $\mathrm{F}$ & ONS \\
\hline CCGs per LA & Number of CCGs each LA is interacting with & $\mathrm{F}$ & Gov \\
\hline CCG dummy & $\begin{array}{l}1 \text { - April } 2013 \text { onwards, identifies creation of } \\
\text { CCG's, } 0 \text { - before April } 2013\end{array}$ & $\mathrm{~F}$ & Gov \\
\hline
\end{tabular}

Note: Q - quarterly, A - annual, F - fixed; NHS/E - NHS England, CQC - Care Quality Commission, ONS - Office for National Statistics, LandReg - HM Land Registry's Price Paid Data, Gov - UK government's online service. 